\title{
Spiritual and Religious Support for Underrepresented First-Generation, Low-Income (UFGLI) Students
}

\author{
Elliott Ingersoll ${ }^{1, *}$, Sophia Elliott ${ }^{2}$ and Stephanie Drcar ${ }^{1}$ \\ 1 Department of Counseling, Administration, Supervision \& Adult Learning, Cleveland State University, \\ Cleveland, OH 44115, USA; s.drcar@csuohio.edu \\ 2 Center for Urban Education, Cleveland State University, Cleveland, OH 44115, USA; \\ s.m.elliott26@vikes.csuohio.edu \\ * Correspondence: r.ingersoll@csuohio.edu
}

check for updates

Citation: Ingersoll, Elliott, Sophia Elliott, and Stephanie Drcar. 2021. Spiritual and Religious Support for Underrepresented First-Generation, Low-Income (UFGLI) Students. Religions 12: 548. https://doi.org/ $10.3390 /$ rel12070548

Academic Editor: Kelvin Mutter

Received: 19 May 2021

Accepted: 10 July 2021

Published: 19 July 2021

Publisher's Note: MDPI stays neutral with regard to jurisdictional claims in published maps and institutional affiliations.

Copyright: (c) 2021 by the authors. Licensee MDPI, Basel, Switzerland. This article is an open access article distributed under the terms and conditions of the Creative Commons Attribution (CC BY) license (https:// creativecommons.org/licenses/by/ $4.0 /)$.

\begin{abstract}
UFGLI students comprise 34\% of the students enrolled in four-year universities. Unlike some students, UFGLI students face internal and systemic barriers throughout their educational experience and their struggles are often dismissed and disregarded. Working and raising a family while taking courses, minimal support systems, and financial struggles require students to optimize their resources. We explore the issues of UFGLI students and the importance of their spiritual and religious supports using a literature review and a case study. Religious and spiritual identities are resources that should be explored and supported by staff at university counselling centers. Affirming UFGLI students' religious and spiritual identities and understanding how religion and spirituality work in their lives can assist these students in their acclimation to and success at university.
\end{abstract}

Keywords: religious identity; spiritual practices; underrepresented; first-generation; low-income; minority

In the United States, underrepresented first-generation, low-income (UFGLI) students are those who hold a minority racial/ethnic identity and are enrolled in a four-year university, that are living beneath the poverty line, and who do not have parents who have completed a four-year degree (Engle and Tinto 2008; Tate et al. 2015). This paper is aimed at counsellors in college counselling centers who have many opportunities to work with these students. First-generation college students comprise roughly $50 \%$ of all college students and approximately $34 \%$ of individuals enrolled in 4-year universities (Hébert 2018). These students are disproportionately racial minority group members and individuals from low-income backgrounds (Hébert 2018). Even though religious identity as indicated by church membership has fallen below the majority in the U.S. (Jones 2021), religious and spiritual identity continue to be important in the lives of young UFGLI students such as African Americans coming from low-income families (Nguyen et al. 2019).

It is important to note that UFGLI students are also for the most part BIPOC ("black, indigenous and people of color"). The first recorded instance of the BIPOC acronym is in a 2013 post on the social media network Twitter (Garcia 2020). Scholars in different societies should reflect on these acronyms and whether they are doing the work intended. For example, in Canada, Indigenous people were colonized (often with horrific outcomes) although not enslaved whereas Africans were enslaved in many countries (Garcia 2020). In the United States, Indigenous and enslaved people had different experiences and some scholars suggest that to conflate all these populations is in essence to erase each group's uniqueness. Chelsey Luger, a member of Turtle Mountain Band of Chippewa, a tribal nation in North Dakota claims that trying to represent multiple identities in one acronym is colonialism itself. Further, she notes that like the terms "Native American" or "First Nations", BIPOC artificially creates a homogeneous whole out of a diversity of groups (Garcia 2020). As such, BIPOC (and UFGLI we anticipate) are not without controversy, many believing such acronyms are coined by Whites who have been "the engineers of the English language for centuries" (Wright 2021, p. 2). We have chosen UFGLI because 
it speaks specifically to those variables counsellors and college counselling centers can address with these students: being under-represented, first-generation, and coming from low-income socio-economic strata.

Even though spiritual and religious identities are a prime resource for these students, in studies about diversity at university, religion and spirituality were often not adequately addressed (Bowman and Smedley 2013; Sanchez et al. 2018a). Scholars contend that religious affiliation is an overlooked variable that can be associated with student outcomes at university (Bowman and Smedley 2013; Bowman and Small 2012). Using a sample of 3098 undergraduate students across 28 institutions, Bowman and Smedley (2013) found that students with no religious affiliation were least satisfied with their overall higher education experience, Black students were less satisfied than their White counterparts, and Protestant students were most satisfied. They also found that students with minority religious status were among the least satisfied with their university experience but that many White students with religious minority status, may simply "hide" this aspect of their identities to "pass" as majority students believing that may help their socioeconomic goals. Due to social acceptance of the construct of race, UFGLI students do not have this option.

Religious diversity is a cultural reality that staff at university counselling centers will encounter in their work. In addition, students who meet one, two, or all three of the UFGLI identities report the benefits of religious/spiritual identity and some research correlates these identities with positive academic outcomes (Fife et al. 2011). As such, understanding the importance of religion and spirituality is a useful competency for staff at university counselling centers (Aten and Leach 2009; Richards and Bergin 2000). For example, it is reported that fifty-nine percent of African Americans are affiliated with what are called "black churches" (Sahgal and Smith 2009). This refers to institutions that include local, African American churches led by African American pastors. Black churches are examples of a unique cultural and foundational cornerstone of some UFGLI students (Avent Harris and Wong 2018) that university counsellors can learn about and help students draw upon. As a plurality, Black churches represent a way of thinking about spirituality that shape students' lives grounded in the lived knowledge of the Black experience.

Because the intersectionality of UFGLI student identities is relatively new, we will summarize research on subjects who meet all three identities as well as related studies on subjects who may only meet criteria for one or two of the identities. We use the phrase religious and spiritual identities in this paper because research suggests a great deal of overlap across these constructs (Berkel et al. 2004). While many non-Hispanic White students are more likely to identify as "spiritual but not religious", UFGLI students are more likely to state that they are both religious and spiritual (Chatters et al. 2008).

\section{Introduction to the Population}

UFGLI students represent the intersection of three marginalized identities: identifying as a racial/ethnic minority, one's parents have not attended or completed college, and they are living below the poverty line (Tate et al. 2015). Counselling literature is just beginning to examine these three identities in unison regarding approaches to commonly faced educational and personal challenges. As such, we hope that focusing on UFGLI students' religious and spiritual lives will add to this literature. When considering the unique challenges each identity faces, it is easy to identify the need UFGLI students have for clinical support holding all three of these identities. Given that religious and spiritual beliefs/practices are an important resource for these students across their lifespan ( $\mathrm{O}^{\prime} \mathrm{Brien}$ et al. 2019; St. Vil et al. 2016), we aim in this paper to offer ideas regarding how university counselling center staff and community members can support them.

Students that identify as first generation are more likely to be classified as nontraditional with characteristics and experiences unique from traditional students (Stebleton et al. 2014). Minority individuals from low-income backgrounds disproportionately represent this first-generation population (Hébert 2018). First-generation and low-income students are more often single parents and are employed because they are not financially 
dependent on their parents (Stebleton et al. 2014). They are more likely to delay college, live off campus, participate in fewer extracurricular programs, enroll in fewer credit hours, and hold a lower GPA (Hébert 2018; Stebleton et al. 2014).

These students tend to have lower ratings of sense of belonging and satisfaction at university than non-first-generation students (Stebleton et al. 2014). Maintaining multiple oppressed identities often creates a feeling of being an outsider amongst their peers (Stebleton et al. 2014). In fact, Stebleton et al. (2014) found that UFGLI students were nearly four times more likely ( $26 \%$ to $27 \%$ ) to leave higher education after the first year than non-first-generation students. Considering these statistics and the negative effects underrepresented students experience due to imposter phenomenon and perceived stress related to racism, (Chao et al. 2012; Peteet et al. 2015) there is a need for intervention and support. These students can be encouraged to seek out religious/spiritual supports on and around campus. Counselling center staff can support UFGLI students by keeping track of such resources available to them, creating resources if few exist, and encouraging UFGLI students to engage. One way to do this is for campus counsellors to forge alliances with religious groups UFGLI students identify with. We discuss this idea more below.

\subsection{Challenges Faced by UFGLI Students and Their Use of Religious/Spiritual Supports}

Many foundational factors can lead to internal and systemic barriers UFGLI students encounter while pursuing higher education (Tate et al. 2015). When examining the factors that have the largest impact overall, racial/ethnic identity, family income, and parental education tend to have the most significance for surmounting barriers (Tate et al. 2015). Cultural, academic, and social transitions also create hurdles for students upon entering university (Stebleton et al. 2014). In addition, students also need access to social capital which facilitates upward mobility and guides a student's career trajectory (Parks-Yancy 2012).

UFGLI students are experiencing the challenges of intersectionality at three different oppressed intersecting identities (Tate et al. 2015). College students who identify with these intersecting identities are faced with career development struggles and complete college at much lower rates than their counterparts (Tate et al. 2015). This mirrors study results that UFGLI students regularly experience serious psychological distress (Mouzon et al. 2016) that can be partially diffused with religious/spiritual supports (McIntosh 2015). University counselling center staff can also build bridges for these students by allying with college campus and local ministries as they provide more religiously focused counselling and support (Aten 2004).

Oviedo (2019) wrote that religion offers meaning and purpose to the lives of many people and that meaning occurs in the anthropological, historic, and semantic realms. The first two seem most relevant for UFGLI students. Anthropologically, religion provides meaning in life (as opposed to a meaningless life). Historically, the ancestors of these students were oppressed, marginalized, and in many cases enslaved. As such, their ancestors did not have access to direct texts of the Christian religion they were forced to assimilate. The resulting adaptations are thought to account for variations in worship and tradition (Marty and Appleby 1991) that constitute the culture of many Black churches. In many cases, UFGLI students may seek out campus ministries before counselling so a good working relationship between said ministries and counselling centers is critical (Gill et al. 2010).

Davidson et al. (2020) illustrated such alliances in their work with campus ministry leaders. They conducted semi-structured interviews with twelve campus ministry leaders with their experiences with students who had mental health concerns. Ministers reported providing pastoral care, concrete interventions such as transportation during crises, and a desire to be more fluent in mental health issues. Aten (2004) suggested that campus ministries could provide internship sites for students studying mental health thus providing an interface between religion and mental health. Both are promising efforts that can provide services to UFGLI students while sharing knowledge across the boundaries of religious institutions and mental health professions. 
Although the dominant culture can be a foundational barrier for UFGLI students, religious culture has been identified as a strength of UFGLI students' experience in Black churches (Avent Harris and Wong 2018). The culture of Black churches was divided into three subthemes: family and community, foundation, and the uniqueness of the congregations. Family includes church family and those members of the church family who have been to university can provide important mentoring to UFGLI students. This mentoring can include encouraging students to take advantage of campus ministry and counselling resources. Foundation refers to the church being part of UFGLI students lives for as long as they can remember. Counselors need to understand the importance of this foundation and how students draw strength from it. Finally, counselors need to understand what the uniqueness of the culture of Black churches means to UFGLI students individually.

This brings us back to the importance of college counselling centers forging alliances with Black churches around their university. Avent Harris and Wong (2018) found that African American students would be more likely to begin seeking help in the church rather than counselling. Because of this, counselors should utilize what Faiver et al. (2001) refer to as "friendly clergy." In this case these would be African American clergy in Black churches near university who could serve as resources for UFGLI students as well as help UFGLI students decide whether they wish to pursue support at college counselling centers. These friendly clergy alliances can help UFGLI students maintain a sense of connection to the religious/spiritual aspects of their lives.

UFGLI students are impacted in areas beyond academics, highlighting the importance of approaching these students with awareness of their experiences as whole persons (even outside of the university). As mentioned, these students are living below the poverty line (Tate et al. 2015). This creates an inevitable shift in priorities, ultimately pulling from a student's ability to be fully engaged in their studies and impacting their mental health. It is difficult for a student to engage in studying while struggling for food and shelter, and working overtime limiting time to engage in self-care. First-generation students are often non-native English speakers, non-traditional, single parents, and not financially dependent on their parents (Stebleton et al. 2014). They work more hours (work full time and go to school part time) and have an income of under \$25,000 per year (Hébert 2018; Stebleton et al. 2014). Considering this, counselling center staff need to maintain a resource list of where students can receive assistance with emergency loans, housing, and childcare while at university.

This brings us to the relationship between economic inequity, power, and religiosity. This has been studied as part of the sociology of religion. Navarro and Skirbekk (2018) noted that in societies with a majority of religiously unaffiliated people, income distribution is more equal than in many societies with a majority of religiously affiliated people. The extent to which economic inequality correlates with religious and spiritual devotion was explored using deprivation theory (Glock 1964) and relative power theory (Solt et al. 2011). Deprivation theory focuses on religion's value to the poor and how the church community can provide material assistance to those in need. It also posits that people in difficult financial circumstances are more likely to turn to religion for comfort. Another way of stating this is that atheism or agnosticism are often perspectives rooted in privilege (Subisatti 2018). Relative power theory acknowledges these dynamics between the church and the poor while also focusing on religion's utility to the rich. Deprivation theory predicts that more inequality is expected to increase religiosity in poorer members of society. The common explanation is that religion provides reassurance and material support in times of hardship (Scheve and Stasavage 2006). Relative power theory also assumes that those with fewer resources will gravitate toward religion for reassurance and postulates that those who qualify as rich, will also gravitate toward religion as a means of social control in which they attempt to cast the economic narrative as Divinely ordained.

The latter strategy is sometimes called "Deuteronomical Theology" in reference to passages in the book of Deuteronomy (meaning "second law") that refer to the righteous 
being rewarded and the wicked being punished. Most religious scholars agree it is a misuse of the text (Spong 1991). As regards deprivation theory, counselling center staff should be prepared to familiarize themselves with the religious/spiritual lives of their UFGLI students and how they might receive material and spiritual support when needed. Regarding relative power theory, counsellors need to be prepared to engage in social justice work to address inequities and oppose the efforts of those who would hijack religion to justify economic inequality.

When exploring the academic barriers UFGLI students (and students identifying with one or more of these identities) often experience, negative implications at a systemic level become evident. First-generation low-income students tend to enter college less academically prepared because of a less rigorous curricula being enforced in high school as well as being less likely to enroll in Advanced Placement (AP) courses (Hébert 2018). Americans of low socioeconomic status are less likely to complete high school, enroll at a university, and earn a college degree than middle and higher SES students (Ou and Reynolds 2014). First-generation low-income students are more likely to delay college after high school, live off campus in higher rates, and attend classes closer to home. They do not participate in as many extracurricular programs or events, they enroll in and earn fewer credit hours than their counterparts, and overall, they hold lower GPAs (Hébert 2018; Stebleton et al. 2014).

In addition to these statistics, first-generation students are more than twice as likely to leave university prior to their second year and without earning a degree and were nearly four times less likely (26\% to $27 \%$ ) to return to university (Hébert 2018; Stebleton et al. 2014). These findings suggest two courses of action: one that can be enacted in community churches before an UFGLI student gets to university and a second after they arrive at university. Since UFGLI students may be hesitant to seek out counselling services (Dobalian and Rivers 2008), mentoring in the church prior to attending university can help. Erickson and Phillips (2012) found that religious youth who receive mentoring are more likely to complete high school and enroll in college. As noted above, college counsellors familiarizing themselves with UFGLI student needs and culture can benefit from alliances with friendly clergy and churches that serve UFGLI students.

While a good portion of literature tends to highlight how foundational barriers negatively affect the educational pursuits and retention of UFGLI students, the barriers associated with these intersecting identities are also known to lead to poor mental health (Tate et al. 2015). For example, first-generation students are more likely to feel as though they do not belong on campus and less like they matter within the educational system (Stebleton et al. 2014). In fact, researchers often discuss the challenge faced by these students of being a part of two cultures and identities, but not belonging to either (Stebleton et al. 2014). Affirming the religious/spiritual identities of these students contributes to them feeling seen and a part of a university community.

Stebleton et al.'s (2014) findings indicate that "first-generation students tend to have lower ratings of sense of belonging and satisfaction than non-first-generation students" (p. 14). Sense of belonging is defined as "a construct that can be defined as a need or desire to be connected through formal and informal interactions" (Stebleton et al. 2014, p. 8). This feeling of lacking belonging could be attributed to lack of social participation (Stebleton et al. 2014). UFGLI students have other pressing obligations such as working while balancing coursework and trying to survive on a low income. These responsibilities may keep them away from campus and social opportunities. This could also be attributed to the fact that these students maintain multiple oppressing identities that create a feeling of being an outsider amongst their peers (Stebleton et al. 2014). College counselling centers may consider tailoring support groups to UFGLI students using convenient formats such as remote audio-video sessions. These could be synchronous and recorded so that those with scheduling conflicts could still hear how others are coping and what is working for them.

Stebleton et al. (2014) also found that sense of belonging is significantly associated with levels of depression and stress. They found that UFGLI students "have a higher frequency 
of reporting feeling stressed, depressed, or upset compared with non-first-generation students" (Stebleton et al. 2014, p. 14). First-generation students also report significantly more somatic characteristics and lower levels of self-efficacy than their non-first-generation counterparts (Stebleton et al. 2014). Ideally, college counsellors and friendly clergy can assist in reconciling the sense of alienation underlying these symptoms. This also involves making sure universities have vibrant student life chapters and activities that appeal to UFGLI students. These may be linked to the church and include support activities such as attending church with other UFGLI students. Students report such activities decrease their feelings of alienation (Avent Harris and Wong 2018).

It should also be noted that underrepresented students often feel the effects of imposter phenomenon during their time pursuing a higher education (Peteet et al. 2015). This phenomenon is described as an internal feeling of intellectual phoniness (Peteet et al. 2015). To students experiencing this, it often feels as though others have been fooled into overestimating their intellectual ability (Peteet et al. 2015). Imposter phenomenon can cause a decrease in academic participation, resulting in the avoidance of situations involving evaluation. This can cause students to consistently feel insufficient with a constant nagging pressure to achieve (Peteet et al. 2015). UFGLI support groups can help normalize the imposter phenomenon and share ideas for working through it.

Sanchez et al. (2018b) also found peer mentoring can help students move through the experience of imposter syndrome. They found that five program processes increased the success and longevity of peer-mentoring programs. These were rapport-building exercises, safe spaces, teaching mutual support, acknowledging group identity, and reported levels of trust. Kazerooni et al. (2020) have also noted that during the COVID-19 pandemic (and in the aftermath) such mentoring relationships can be established on social media platforms. Because of the multiple demands on their time, such platforms may be beneficial to the schedules of UFGLI students.

\subsection{Strengths of UFGLI Students}

Despite facing major adversity, UFGLI students succeed by marshalling and using resources including religious and spiritual identities. For example, many studies often present first-generation students as succeeding throughout college and earning their degree despite their family background (Gofen 2009). There is evidence to suggest that UFGLI students' families are a positive and motivating influence on their academic goals and achievement (Gofen 2009). Research indicates that although the students face many material challenges, the families of first-generation students are a central resource to reaching their goals rather than a limitation (Gofen 2009).

One of UFGLI students' most significant motivators for pursing high education is the ability to later be able to help their families (Bui 2002). Coming from lower income homes, UFGLI students feel they do not have an option when it comes to succeeding. They are often their family's key to exiting poverty and that is a huge motivational factor for being successful in college. To further these claims, Bui (2002) found that "first-generation college students express greater fear of failing in college, worry more about financial aid, and feel they have to put more time into studying" (p. 10). Again, this can potentially be attributed to the strong drive to provide for their families and give back to their parents. This can be a barrier due to the extra stressors associated with this identity, however, this reality can also give students a strong push toward success. Counselling center staff, knowing this about UFGLI students, can help them reframe this sentiment in ways that maximize the motivational component and minimize the stress component.

This raises the related issue of mentoring UFGLI students regarding university costs and student loans. The financial burdens of cost and student loans are higher for UFGLI students (Kim et al. 2017). In addition, for-profit institutions target UFGLI students with heavily financed recruitment networks that offer students attention during the recruitment process but the attention then drops off after the student begins the program. For-profit incentives that can be appealing to UFGLI students include open admission policies, 
flexible academic schedules, online instruction, and programs in career-relevant fields. These institutions also may seek to increase their revenues in ways that are not beneficial to UFGLI students such as using accreditation costs to inflate tuition (Gelbgiser 2018).

Given these issues, ideally UFGLI students can be mentored before attending University and while enrolled. At the university level, this would require faculty, advisors, and counselors to be literate in financial aid. Fiscal literacy includes being able to compare anticipated salaries post-graduation with the amount that is fiscally feasible to borrow to earn the degree. June (2016) suggested the creation of bridge mentors for UFGLI students. These are mentors that can come from university and surrounding religious institutions that help bridge racial and cultural divisions to make campuses more welcoming. These mentors would also be literate in financial aid so they can help the student understand any gaps between what recruiters may say and what a particular field can offer as well as the intricacies of student loans.

\section{Case Study}

We wanted to provide a case example of how institutions can forge alliances to address the needs of UFGLI students. In retrospect, this case is a good example of what Holcombe and Kezar (2020) call a "unified community of support" (Holcombe and Kezar 2020, p. 349) that includes students, faculty, and staff. Our case study is drawn from the experience of a medium-sized university (5000-15,000 students) in an urban center in the Midwest. We will call the institution City College U. Beginning in 2017, City College $\mathrm{U}$ had an annual retreat in late summer that involved the Counselling Center, Campus Ministries (non-denominational), The Newman Center (Roman Catholic), and the African Methodist Episcopal (AME) Church downtown. The retreats were initially organized to meet the needs of the many UFGLI students who lived in the urban area and attended City College U.

The first retreat was led jointly by the Counselling Center and the AME Church. The pastor of the AME Church had developed a mentoring program at the church for young people who wanted to attend university. She felt that by forging an alliance with the Campus Counselling Center, she would be introducing resources that the young people in her parish would need to succeed at university. The Director of the Counselling Center was interested in forging an alliance with other representatives of area Black churches to expand the religious and spiritual supports for UFGLI students.

The first retreat utilized rapport building exercises, discussion of safe spaces, and mutual support for students both in university, and those who wished to attend someday. The most tangible result of the first retreat was a program that was called "Praise and Success" (PAS). The PAS program provided transportation from campus to churches on Sundays for UFGLI students who wanted to worship at three historically Black churches around campus, including the AME Church. The costs of the transport were paid with a grant the Counselling Center was awarded.

At the 2018 retreat, it was reported that two-hundred eighty students used the transport to attend services in town. At the 2018 retreat, the group focused on mentoring for those students aspiring to attend. The mentoring took place at the AME Church for aspiring students and at the Counselling Center for current students. Twelve faculty with counselling or psychotherapy backgrounds were recruited to provide Wednesday and Thursday mentoring sessions where they met with sixteen and seventeen-year-olds from the community who have UFGLI backgrounds. The faculty rotated to provide sessions every other week for eight weeks in the fall semester and eight weeks in the spring semester.

At the 2019 retreat, the mentoring program had served ninety-four aspiring students. Of the ninety-four, fifty-eight were seventeen years old and of them, thirty-two had successfully applied to university. At the time of the 2019 retreat, twenty-four of those had been accepted. At the 2019 retreat, The Newman Center withdrew from the group as their personnel had been reduced and they did not have sufficient time to participate. The focus of the 2019 retreat was to bring more focused support for UFGLI students on campus. 
The result was an Academic Success Program that provided weekly sessions for UFGLI students with counsellors and some volunteers of the AME Church. The plan was to be launched in 2020 but was put on hold due to the coronavirus pandemic.

\section{Limitations \& Implications for Future Research}

In this paper we have aimed to introduce readers to UFGLI students, the challenges they face, and how religious and spiritual resources can serve them in their quest to earn university degrees. As noted, the concept of the UFGLI student and their intersecting identities is newer so some of our searches in the literature of religious and spiritual supports broke the intersecting identities into single identities (e.g., under-represented students) or combined two of the intersecting identities (e.g., first-generation, underrepresented students). In addition, the extent to which acronyms (e.g., UFGLI, BIPOC) are useful or artificially group diverse peoples together in a way that diminishes their uniqueness should be considered.

One topic of future research that would be useful is definitively clarifying where these acronyms come from, the extent to which they are accepted or embraced by the people they refer to, and whether they are useful for research purposes. Hopefully, researchers will continue to explore whether the intersectionality of identities also creates problems and solutions unique to the UFGLI population. A more systematic approach to studying interventions like those described in the case study would be useful. In addition, recent research (Bassett 2021) has begun examining variables that predict UFGLI students' success in benefitting from support programs. Bassett found that the extent of students' helpseeking orientation and the strength of the relationship with program staff predicted favorable outcomes. The help-seeking orientation most correlated with academic success was seeing reaching out as a strength rather than a weakness. Finally, more research is needed exploring with students who fit into the UFGLI identities as to what they need, what has supported them, and what has not worked for them. Qualitative dialogue may yield more on this front than studies utilizing inventories and questionnaires.

\section{Conclusions}

Overall, although UFGLI students face deficits in structural supports, they can rely on religious and spiritual communities for support. Although we are aware of the educational, emotional, and systemic disparities among UFGLI students, helping students to successfully reach their goals and break down these systemic barriers continues to be a challenge. It is our duty as counsellors to recognize UFGLI students' strengths and provide support and psychoeducation to students during this critical transitional time in their lives. Through encouraging mentoring programs, strong alliances between college counselling centers and religious organizations, and cultivating awareness of UFGLI student issues, counsellors can help these students succeed academically.

Author Contributions: Conceptualization, E.I., S.E., and S.D.; methodology, E.I.; investigation, E.I. and S.E.; resources, E.I., S.E., and S.D.; writing—original draft preparation, E.I. and S.E.; writingreview and editing, E.I., S.E., and S.D.; supervision, E.I. and S.D. All authors have read and agreed to the published version of the manuscript.

Funding: This research received no external funding.

Institutional Review Board Statement: Not applicable.

Informed Consent Statement: Not applicable.

Data Availability Statement: Not applicable.

Conflicts of Interest: The authors declare no conflict of interest. 


\section{References}

Aten, Jamie D. 2004. The college campus ministry internship site: Interfacing religion and counselling. Counselling and Values 49: 64-72. [CrossRef]

Aten, Jamie D., and Mark M. Leach. 2009. A primer on spirituality and mental health. In Spirituality and the Therapeutic Process: A Comprehensive Resource from Intake to Termination. Edited by Jamie D. Aten and Mark M. Leach. Washington, DC: American Psychological Association.

Avent Harris, Janeé R., and Christine D. Wong. 2018. African American college students, the Black Church, and Counselling. Journal of College Counselling 21: 15-21. [CrossRef]

Bassett, Becca Spindel. 2021. Big enough to bother them? When low-income, first-generation students seek help from support programs. Journal of College Student Development 62: 19-36. [CrossRef]

Berkel, LaVerne A., Tonya D. Armstrong, and Kevin O. Cokley. 2004. Similarities and differences between and spirituality in African American college students: A preliminary investigation. Counselling and Values 49: 2-10. [CrossRef]

Bowman, Nicholas A., and Jenny L. Small. 2012. Exploring a hidden form of minority status: College students' religious affiliation and well being. Journal of College Student Development 53: 491-509. [CrossRef]

Bowman, Nicholas A., and Cynthia Toms Smedley. 2013. The forgotten minority: Examining religious affiliation and university satisfaction. Higher Education 65: 745-60. [CrossRef]

Bui, Khanh Van T. 2002. First-generation college students at a four-year university: Background characteristics, reasons for pursuing higher education, and first-year experiences. College Student Journal 36: 3-11.

Chao, Ruth Chu-Lien, Brent Mallinckrodt, and Meifen Wei. 2012. Co-Occurring presenting problems in African-American college clients reporting racial discrimination distress. Professional Psychology: Research and Practice 43: 199-207. [CrossRef]

Chatters, Linda M., Robert Joseph Taylor, Kai McKeever Bullard, and James S. Jackson. 2008. Spirituality and subjective religiosity among African Americans, Caribbean Blacks and non-Hispanic Whites. Journal for the Scientific Study of Religion 47: 725-37. [CrossRef] [PubMed]

Davidson, Charis, Gabrielle M. Turner-McGeivy, DeAnne K. Hilfinger Messias, Daniela B. Friedman, Alyssa G. Robillard, Jessica Schwiesow, and Peter Warren. 2020. Campus ministry leaders promoting student mental health at a large public university in the Southeast United States. Mental Health, Religion \& Culture 23: 67-79.

Dobalian, Aram, and Patrick A. Rivers. 2008. Racial and ethnic disparities in the use of mental health services. The Journal of Behavioral Health Services \& Research 35: 128-41.

Engle, Jennifer E., and Vincent Tinto. 2008. Moving beyond Access: College Success for Low-Income, First-Generation Students. Washington: The Pell Institute.

Erickson, Lance D., and James W. Phillips. 2012. The effect of religious-based mentoring on educational attainment. More than just a spiritual high? Journal for the Scientific Study of Religion 51: 568-87. [CrossRef]

Faiver, Christopher, R. Elliott Ingersoll, Eugene O'Brien, and Christopher McNally. 2001. Explorations in Counseling and Spirituality: Philosophical, Practical and Personal Reflections. Pacific Grove: Brooks/Cole.

Fife, John E., Sherrod Bond, and Angela Byars-Winston. 2011. Correlates and predictors of academic self-efficacy among African American students. Education 132: 141-48.

Garcia, Sandra E. 2020. Where did BIPOC come from? New York Times. June 17. Available online: https:/ / www.nytimes.com/article/ what-is-bipoc.html (accessed on 7 April 2021).

Gelbgiser, Dafna. 2018. College for all, degrees for few: For-profit colleges and socioeconomic differences in degree attainment. Social Forces 96: 1785-824. [CrossRef]

Gill, Carmen S., Casey A. Barrio-Minton, and Jane E. Myers. 2010. Spirituality and religiosity: Factors affecting wellness among low-income rural women. Journal of Counselling E Development 88: 293-302.

Glock, Charles Y. 1964. The role of deprivation in the origin and evolution of religious groups. In Religion and Social Conflict. Edited by Robert Lee and Martin E. Marty. Oxford: Oxford University Press, pp. 24-36.

Gofen, Anat. 2009. Family capital: How first-generation higher education students break the intergenerational cycle. Family Relations: An Interdisciplinary Journal of Applied Family Studies 58: 104-20. [CrossRef]

Hébert, Thomas P. 2018. An Examination of High-Achieving First-Generation College Students From Low-Income Backgrounds. Gifted Child Quarterly 62: 96-110. [CrossRef]

Holcombe, Elizabeth, and Adrianna Kezar. 2020. Ensuring success among first-generation, low-income, and underserved minority students: Developing a unified community of support. American Behavioral Scientist 64: 349-69. [CrossRef]

Jones, Jeffrey M. 2021. U.S. Church Membership Falls below Majority for the First Time. Gallup: Politics. Available online: https: //news.gallup.com/poll/341963/church-membership-falls-below-majority-first-time.aspx (accessed on 18 April 2021).

June, Audrey Williams. 2016. Building bridge leaders for minority professors and students. Chronicle of Higher Education 62: 9.

Kazerooni, AmirAli Rastegar, Mitra Amini, Parinaz Tabari, and Mahsa Moosavi. 2020. Peer mentoring for medical students during the COVID-19 pandemic via a social media platform. Medical Education 54: 762-63. [CrossRef] [PubMed]

Kim, Jinhee, Swarn Chatterjees, J. Young, and U. J. Moon. 2017. The cost of access: Racial disparities in student loan burdens of young adults. College Student Journal 51: 99-114.

Marty, Martin E., and R. Scott Appleby, eds. 1991. Fundamentalisms Observed. Chicago: University of Chicago Press. 
McIntosh, Erin James. 2015. Thriving in college: The role of spirituality and psychological sense of community in students of color. About Campus 19: 16-23. [CrossRef]

Mouzon, Dawne M., Robert Joseph Taylor, Ann W. Nguyen, and Linda M. Chatters. 2016. Serious psychological distress among African Americans: Findings from the national survey of American life. Journal of Community Psychology 44: 765-80. [CrossRef] [PubMed]

Navarro, Jose, and Vegard Skirbekk. 2018. Income inequality and religion globally: 1970-2050. Scripta Institati Donneriani Aboensis 28: 175-99. [CrossRef]

Nguyen, Ann W., Robert Joseph Taylor, Linda M. Chatters, and Meredith O. Hope. 2019. Church support networks of African Americans: The impact of gender and religious involvement. Journal of Community Psychology 47: 1043-63. [CrossRef] [PubMed]

O'Brien, Brittany, Srijana Shrestha, Melinda A. Stanley, Kenneth I. Pargament, Jeremy Cummings, Mark E. Kunik, Terri L. Fletcher, Jose Cortes, David Ramsey, and Amber B. Amspker. 2019. Positive and negative religious coping as predictors of distress among minority older adults. International Journal of Geriatric Psychiatry 34: 54-59. [CrossRef]

$\mathrm{Ou}$, Suh-Ruu, and Arthur J. Reynolds. 2014. Early determinants of post-secondary education participation and degree attainment: Findings from an inner-city minority cohort. Education and Urban Society 46: 474-504. [CrossRef] [PubMed]

Oviedo, Lluis. 2019. Meaning and religion: Exploring mutual implications. ScientiaetFidees 7: 25-46. [CrossRef]

Parks-Yancy, Rochelle. 2012. Interactions into opportunities: Career management for low-income, first-generation, African American college students. Journal of College Student Development 53: 510-23. [CrossRef]

Peteet, Bridgette J., LaTrice Montgomery, and Jerren C. Weekes. 2015. Predictors of imposter phenomenon among talented ethnic minority undergraduate students. Journal of Negro Education 84: 175-86. [CrossRef]

Richards, P. Scott, and Allen E. Bergin. 2000. Toward religious and spiritual competency for mental health professionals. In Handbook of Psychotherapy and Religious Diversity. Edited by P. Scott Richards and Allen E. Bergin. Washington: American Psychological Association, pp. 3-26.

Sahgal, Neha, and Greg Smith. 2009. A Religious Portrait of African Americans. Retrieved from The Pew Research Center Website. Available online: http/ / www.pewforum.org/2009/01/30/a-religious-portrait-of-african-americans (accessed on 3 April 2021).

Sanchez, Bernadette, Kevin D. Pinkston, Adina C. Cooper, Carlos Luna, and Shelby T. Wyatt. 2018a. One falls, we all fall: How boys of color develop close peer mentoring relationships. Applied Developmental Science 1: 14-28. [CrossRef]

Sanchez, Jefeth E., Lydia DeFlorio, Lynda R. Wiest, and Eleni Oikonomidoy. 2018b. Student perceptions of inclusiveness in a college of education with respect to diversity. College Student Journal 8: 397-409.

Scheve, Kenneth, and David Stasavage. 2006. Religion and preferences for social insurance. Quarterly Journal of Political Science 1: 255-86. [CrossRef]

Solt, Frederick, Philip Habel, and J. Tobin Grant. 2011. Economic inequality, relative power, and religiosity. Social Science Quarterly 92: 447-65. [CrossRef]

Spong, John Shelby. 1991. Rescuing the Bible from Fundamentalism: A Bishop Rethinks the Meaning of Scripture. San Francisco: Harper.

St. Vil, Noelle M., Bushra Sabri, Vania Nwokolo, Kamila A. Alexander, and Jacquelyn C. Campbell. 2016. A qualitative study of survival strategies used by low-income black women who experience intimate partner violence. Social Work 62: 63-71. [CrossRef]

Stebleton, Michael J., Krista M. Soria, and Ronald L. Huesman. 2014. First-generation students' sense of belonging, mental health, and use of counselling services at public research universities. Journal of College Counselling 17: 6-20. [CrossRef]

Subisatti, Andrea. 2018. The Faculty of Horror Podcast. Episode 60: Season of the Witch: Witches in Film, Part 3. The Witch (2015) and The Autopsy of Jane Doe (2016). Available online: https:/ / www.facultyofhorror.com/tag/the-witch/ (accessed on 13 July 2021).

Tate, Kevin A., Nadya A. Fouad, Laura Reid Marks, Gary Young, Eddie Guzman, and Eric G. Williams. 2015. Underrepresented first-generation, low-income, college students; pursuit of a graduate education: Investigating the influence of self-efficacy, coping efficacy, and family influence. Journal of Career Assessment 23: 427-41. [CrossRef]

Wright, A. 2021. 'BIPOC' Acronym Does Nothing to Address Issues Faced by Black Community. The Daily Telegram. Available online: https:/ / dailytargum.com/article/2021/02/wright-bipoc-acronym-does-nothing-to-address-issues-faced-by-blackcommunity (accessed on 7 January 2021). 